\title{
PENINGKATAN DISPOSISI MATEMATIS DENGAN PENGEMBANGAN PERANGKAT PEMBELAJARAN MATEMATIKA DENGAN MODEL THINKING ALOUD PAIRS PROBLEM SOLVING (TAPPS) BERBASIS MULTIMEDIA
}

\author{
Savitri Wanabuliandari \\ Program Studi Pendidikan Guru Sekolah Dasar \\ Email : savitri.wanabuliandari@umk.ac.id
}

\begin{abstract}
This research is aimed to develop the mathematics learning materials quadrilateral with a model-based Multimedia TAPPS, so that it becomes a valid, practical and effective learning device. The study is also aimed to determine the increase of mathematical disposition. The development of learning device is done by using 4-D Thiagarajan model, which has been modified which include Define, Design, and Develop. The types of learning devices which developed are syllabus, lesson plans, worksheets, and Multimedia. The validity of the learning device is determined based on the expert validation. The Practicality of learning device can be seen from the response of the students, teachers' responses and management teacher learning in the classroom. The effectiveness of learning can be obtained by doing a test device.
\end{abstract}

Keyword: Multimedia, TAPPS, Mathematical disposition

\begin{abstract}
ABSTRAK
Penelitian ini bertujuan mengembangkan perangkat pembelajaran matematika materi segiempat dengan model TAPPS berbasis Multimedia, sehingga menjadi perangkat pembelajaran yang valid, praktis dan efektif. Penelitian ini juga bertujuan untuk mengetahui peningkatan disposisi matematis. Pengembangan perangkat pembelajaran dilakukan dengan menggunakan model 4-D Thiagarajan, yang telah dimodifikasi yaitu meliputi Define, Design, dan Develop. Jenis perangkat pembelajaran yang dikembangkan adalah Silabus, RPP, LKS, dan Multimedia. Kevalidan perangkat pembelajaran ditentukan berdasarkan validasi ahli. Kepraktisan perangkat pembelajaran dilihat dari respon peserta didik, respon guru dan pengelolaan pembelajaran guru di kelas. Keefektifan pembelajaran didapatkan dengan melakukan uji coba perangkat.
\end{abstract}

Kata kunci: Multimedia, TAPPS, Disposisi Matematis

\section{PENDAHULUAN}

Salah satu pembelajaran matematika di sekolah adalah agar peserta didik memiliki sikap menghargai kegunaan matematika dalam kehidupan, yaitu memiliki rasa ingin tahu, perhatian, dan minat dalam mempelajari matematika, serta sikap ulet dan percaya diri dalam penyelesaian masalah. Dari pernyataan tersebut jelas bahwa dalam tujuan pembelajaran terdapat komponen disposisi matematis. Oleh karena itu, disposisi matematis perlu dikembangkan dalam pembelajaran matematika.

Kenyataannya masih banyak peserta didik yang masih merasa bahwa matematika tidak bermanfaat sehingga menyebabkan rendahnya

\section{Jurnal Refleksi Edukatika}

Vol. 6 No. 2 Juni 2016 
kemampuan pemecahan masalah. Kesulitan dalam hal pemecahkan masalah peserta didik dapat disebabkan karena ketidakcermatan dalam membaca soal, ketidakcermatan dalam berpikir, kelemahan analisis masalah, dan kurang gigih dalam menyelesaikan masalah.

Kekurang gigihan dalam menyelesaikan masalah menunjukkan bahwa disposisi matematis peserta didik masih rendah. Menurut Carr, Lane, dan Seuer (Maxwell, 2001: 31) disposisi matematis adalah segala sesuatu yang menyangkut motivasi, rasa ingin tahu, ketekunan, mau mengambil resiko, dan berpikiran terbuka. Disposisi matematis merupakan salah satu faktor yang mempengaruhi peserta didik dalam belajar matematika (Anku, 1996: 1). Menurut Maxwell (2001: 30) disposisi matematis yang rendah dikarenakan peserta didik menganggap matematika tidak diperlukan dalam kehidupan sehari-hari. Pernyataan ini sesuai dengan yang terjadi saat ini. Peserta didik beranggapan matematika sulit, tidak penting, dan tidak menyenangkan. Hal ini menunjukkan bahwa disposisi matematis pada peserta didik masih rendah.

Menurut Carr (Maxwell, 2001: 32), disposisi dan kemampuan adalah dua hal yang berbeda. Bila ada dua peserta didik yang mempunyai kemampuan sama, tetapi memiliki disposisi berbeda, diyakini akan menunjukkan hasil belajar yang berbeda. Peserta didik yang memiliki disposisi yang kuat akan lebih gigih, tekun, dan berminat untuk mengeksplorasi halhal baru, dan sebaliknya. Hal ini sejalan dengan Tishman, Jay dan Perkins (1993: 147) yang sepakat bahwa disposisi yang kuat akan menumbuhkan pikiran peserta didik untuk mengeksplorasi hal-hal baru. Menurut Maxwell
(2001: 32) kesenangan dalam matematika menunjukkan disposisi matematisnya. Jika peserta didik merasa matematika sulit dan kurang menyenangkan berarti menujukkkan disposisi matematis yang rendah.

Berdasarkan hasil wawancara dengan salah satu guru matematika di SMPN 3 Kudus didapatkan hasil bahwa sikap peserta didik terhadap matematika sangatlah kurang. Berdasarkan angket disposisi matematis yang diberikan kepada peserta didik pada pertemuan pertama menunjukkan bahwa respon peserta didik terhadap matematika kurang baik. Hal ini ditunjukkan dari hasil analisis perhitungan yang mendapatkan skor rata-rata 50 padahal skor tertinggi adalah 100. Ini dikarenakan peserta didik beranggapan bahwa matematika sulit artinya peserta didik tidak memiliki sikap percaya diri,gigih dan ulet. Peserta didik juga malas untuk mempelajari kembali atau mencari sumber-sumber lain yang relevan artinya tidak memiliki sikap ingin tahu dan ingin merefleksi cara berpikirnya. Peserta didik juga merasa matematika tidak penting dan tidak berguna artinya tidak memiliki sikap menghargai dan mengapresiasi peranan matematika, sehingga ini menunjukkan bahwa disposisi matematisnya masih rendah.

Rendahnya disposisi matematis juga disebabkan karena guru belum mampu meciptakan pembelajaran yang kreatif, menyenangkan dan aktif, guru belum mengenal macam-macam model pembelajaran dan kurang menguasai teknologi. Di SMPN 3 Kudus guru masih melakukan pembelajaran tanpa alat bantu mengajar, padahal alat bantu mengajar sangat penting dalam penyampaian materi geometri yang bersifat abstrak. Hal ini menyebabkan peserta didik tidak bisa diajak untuk berpikir 
dan beraktifitas untuk mendapatkan sendiri pengetahuannya. Oleh karena itu perlu adanya media pembelajaran yang menyenangkan bagi peserta didik agar muncul disposisi matematis.

Agar disposisi matematisnnya meningkat guru harus melakukan variasi model pembelajaran. TAPPS merupakan model pembelajaran yang cocok untuk peningkatan disposisi matematis peserta didik. Hal ini didukung oleh penelitian dari Tishman, Jay, dan Perkins (1993: 151) yang menjelaskan bahwa dengan menggunakan model TAPPS peserta didik dapat saling berinteraksi dan dapat meningkatkan kemampuan pemecahan masalah. Penggunakan model ini pada peserta didik dapat memunculkan disposisi matematisnya.

Hassard (2000: 36) menjelaskan langkahlangkah model TAPPS adalah sebagai berikut.

1. Peserta didik 1 membaca masalah dengan keras, mencoba menyelesaikan masalah dengan berbicara keras. Peserta didik 2 menjadi pendengar peserta didik 1 . Pendengar tidak memberikan jawaban.

2. Diskusikan hasilnya dikelas tanyakan kebeberapa peserta didik yang menjadi pemecah masalah untuk menjelaskan cara berpikir mereka serta tanyakan komentar dari pendengar.

Visualisasi diperlukan untuk menjelaskan geometri yang bersifat abstrak dan kurang disukai peserta didik. Dengan pembelajaran berbasis multimedia, peserta didik tidak mudah bosan. Konsep pembelajaran dapat dilaksanakan bila informasi tersebut menarik dan memotivasikan peserta didik untuk terus belajar. Ini dapat dicapai jika materi atau informasi diolah dengan baik menggunakan multimedia. Jadi manfaat multimedia adalah menjadikan proses pembelajaran lebih menarik, lebih interaktif, menghemat waktu, memudahkan dalam belajar, dan dapat meningkatkan motivasi belajar peserta didik.

Pengembangan model TAPPS berbasis multimedia bisa menjadi salah satu alternatif untuk variasi pembelajaran. Pelaksanaan model TAPPS berbasis multimedia ini memungkinkan peserta didik bekerja dalam kelompok untuk memecahkan masalah sehingga peserta didik akan di tuntut berperan secara aktif dalam kelompoknya dan dalam hal ini guru berperan sebagai fasilisator dalam pembelajaran. Jadi, peserta didik akan terlibat langsung untuk membangun dan menemukan konsep-konsep sendiri agar pembelajaran lebih bermakna, sehingga akan meningkatkan disposisi matematis.

Penelitian ini bertujuan untuk mendapatkan hasil pengembangan perangkat pembelajaran matematika materi segiempat dengan model TAPPS berbasis multimedia yang valid dan praktis, sehingga diperoleh pembelajaran efektif.

Manfaat penelitian ini adalah (1) meningkatkan profesionalitas guru, memberikan informasi mengenai penggunaan model TAPPS berbasis multimedia (2) melatih agar peserta didik lebih aktif dalam belajar, mengembangkan jiwa kerjasama, menghargai, dan membangun kepercayaan diri, serta meningkatkan disposisi matematis masalah matematika khususnya pada materi segiempat.

\section{METODE PENELITIAN}

\section{Jenis Penelitian}

Penelitian ini termasuk jenis penelitian pengembangan. Pengembangan yang dilakukan adalah perangkat pembelajaran matematika dengan model TAPPS berbasis multimedia untuk meningkatkan disposisi matematis materi segiempat pada peserta didik kelas VII SMP.

\section{Jurnal Refleksi Edukatika}

Vol. 6 No. 2 Juni 2016 
Adapun Perangkat yang dikembangkan berupa Silabus, RPP, LKS, dan Multimedia.

\section{Prosedur Pengembangan Perangkat Pembelajaran \\ Prosedur pengembangan perangkat} pembelajaran yang digunakan adalah memodifikasi model 4-D dari Thiagarajan, Sammel dan Sammel (1974: 5-9). Modifikasi dari Thiagarajan terdiri dari tiga tahap (3-D), yaitu: (1) pendefinisian (define), perancangan (design) dan (3) pengembangan (develop).

a). Rancangan uji coba perangkat pembelajaran

Tabel 1. Rancangan Uji Coba Perangkat (Arikunto, 2002b: 79)

Kelas kontrol $\longrightarrow \mathrm{O}_{1} \longrightarrow \mathrm{X} \longrightarrow \mathrm{O}_{2}$
Kelas eksperimen $\longrightarrow \mathrm{O}_{1} \longrightarrow \mathrm{Z} \longrightarrow \mathrm{O}_{2}$

Keterangan:

$\mathrm{O}_{1}$ : pretest.

$\mathrm{X}$ : Perlakuan dengan model konvensional

$\mathrm{Z}$ : Perlakuan dengan pembelajaran matematika model TAPPS berbasis multimedia. materi segiempat

$\mathrm{O}_{2}$ : posttest.

b). Variabel Penelitian

Tabel 2. Variabel Penelitian

\begin{tabular}{|c|c|}
\hline Hipotesis & Variabel \\
\hline $\begin{array}{l}\text { Hasil perangkat } \\
\text { pembelajaran } \\
\text { matematika materi } \\
\text { segiempat dengan } \\
\text { model TAPPS berbasis } \\
\text { multimedia yang } \\
\text { dikembangkan valid. }\end{array}$ & $\begin{array}{l}\text { Variabel : Kualitas } \\
\text { Perangkat }\end{array}$ \\
\hline $\begin{array}{llr}\text { a. } & \begin{array}{l}\text { Respon } \\
\text { didik peserta } \\
\text { model }\end{array} \\
& \text { terhadap } \\
& \text { berbasis } \\
& \text { multimedia } & \text { baik. } \\
\text { b. } & \text { Respon } \quad \text { guru }\end{array}$ & $\begin{array}{l}\text { a. Variabel : respon } \\
\text { peserta didik } \\
\text { b. Variabel : respon }\end{array}$ \\
\hline
\end{tabular}

\begin{tabular}{|c|c|}
\hline $\begin{array}{l}\text { terhadap model } \\
\text { TAPPS berbasis } \\
\text { multimedia baik. }\end{array}$ & guru \\
\hline $\begin{array}{l}\text { Pembelajaran } \\
\text { matematika materi } \\
\text { segiempat dengan } \\
\text { model TAPPS berbasis } \\
\text { multimedia dapat } \\
\text { meningkatkan disposisi } \\
\text { matematis }\end{array}$ & $\begin{array}{l}\text { a. Variabel bebas: } \\
\text { model TAPPS } \\
\text { berbasis } \\
\text { multimedia } \\
\text { b. Variabel terikat: } \\
\text { disposisi } \\
\text { matematis }\end{array}$ \\
\hline
\end{tabular}

\section{Metode Pengumpulan Data}

Metode pengumpulan data pengembangan yang digunakan dalam penelitian ini adalah sebagai berikut : dokumentasi, angket, dan observasi.

\section{HASIL DAN PEMBAHASAN}

A. HASIL PENELITIAN

1. Proses Uji Validitas Perangkat

\section{Pembelajaran}

lima ahli yang berkompeten untuk menilai kelayakan perangkat pembelajaran. Hasil validasi ahli yang diperoleh seperti pada Tabel 3.

\section{Tabel 3. Hasil Nilai Rata-rata Validasi Ahli}

\begin{tabular}{|c|c|c|c|c|c|c|c|c|}
\hline \multicolumn{2}{|c}{} & \multicolumn{5}{|c|}{ Nilai Validator } & \multirow{2}{*}{$\begin{array}{c}\text { Rat } \\
\text { a }\end{array}$} & Ket \\
\cline { 2 - 8 } & $\mathbf{1}$ & $\mathbf{2}$ & $\mathbf{3}$ & $\mathbf{4}$ & $\mathbf{5}$ & & \\
\hline \multirow{4}{*}{$\begin{array}{l}\text { Nilai } \\
\text { rata- } \\
\text { rata }\end{array}$} & Silabus & 96 & 90 & 90 & 97 & 97 & 94 & $\begin{array}{c}\text { Sanga } \\
\text { t baik }\end{array}$ \\
\cline { 2 - 7 } & LKS & 96 & 94 & 91 & 98 & 97 & 95 & $\begin{array}{l}\text { Sanga } \\
\text { t baik }\end{array}$ \\
\cline { 2 - 7 } & $\begin{array}{l}\text { Multim } \\
\text { edia }\end{array}$ & 97 & 91 & 89 & 97 & 96 & 94 & $\begin{array}{l}\text { Sanga } \\
\text { t baik }\end{array}$ \\
\end{tabular}




\section{Hasil Uji Kepraktisan Perangkat Pembelajaran}

a. Respon Peserta Didik

Hasil jawaban peserta didik yang tertuang dalam angket respon peserta didik mendapatkan respon yang positif.

\section{b. Respon guru}

Data yang ditunjukkan dari respon guru diperoleh hasil: Penilaian Bapak/ Ibu terhadap setiap perangkat pembelajaran dan instrumen menunjukkan hasil yang baik dan sangat baik.

\section{Hasil Uji Efektifitas Perangkat Pembelajaran}

a. Hasil Uji Normalitas Kelas Eksperimen dan Kelas Kontrol

Pada data awal dan akhir pada kelas eksperimen dan kontrol menunjukkan datanya normal.

\section{b. Hasil Homogenitas}

Pada data awal dan akhir pada kelas eksperimen dan kontrol menunjukkan kedua kelompok sampel mempunyai varians yang sama atau homogen.

\section{c. Uji Peningkatan}

Secara rata-rata klasikal diperoleh nilai $\langle g\rangle$ sebesar 0,74 yang berarti tafsiran peningkatan disposisi matematis yang terjadi termasuk kategori tinggi.

\section{B. PEMBAHASAN}

\section{Pembahasan Validasi Perangkat}

a. Validasi terhadap Silabus

Validasi silabus mengacu pada unsur-unsur yang harus ada pada silabus, seperti standar kompetensi, kompetensi dasar, indikator pencapaian materi, kegiatan pembelajaran, media pembelajaran, penilaian, sumber belajar, alokasi waktu, sistem pengembangannya, penggunaan bahasa Indonesia yang baik dan benar, struktur kalimat, serta petunjuk/ arahan. b. Validasi terhadap RPP
Validasi RPP meliputi kelengkapan komponen RPP, perencanaan rumusan tujuan pembelajaran, pengelolaan kelas, penggunaan media pembelajaran, penggunaan standar proses, skenario pembelajaran yang sesuai dengan model TAPPS berbasis multimedia, perencanaan penilaian, dan bahasa yang digunakan.

c. Validasi terhadap LKS

Aspek yang dinilai pada lembar validasi LKS adalah: dapat memunculkan disposisi matematis dan kemampuan pemecahan masalah, kesesuai dengan model TAPPS, kejelasan penomoran, menggugah keingintahuan peserta didik, daya tarik visual, kesesuaian tata bahasa, kalimat dengan taraf berfikir peserta didik, kejelasan petunjuk, dan tidak memuat kalimat ambigu, kebenaran materi, kesesuaian dengan silabus.

d. Validasi terhadap Buku Peserta Didik

Aspek yang dinilai pada lembar validasi buku peserta didik meliputi kesesuai dengan model TAPPS berbasis multimedia, penggunaan huruf dan tata bahasa, kebenaran materi, mendorong minat baca, dapat memunculkan disposisi matematis dan kemampuan pemecahan masalah, kejelasan kalimat.

e. Validasi terhadap Multimedia

Validasi Slide Multimedia meliputi: kelengkapan komponen, kesesuaian dengan tujuan, kebenaran konsep, komponen media pada gambar, tulisan, dan animasi, dapat menggugah keingintahuan peserta didik, dan kesesuaian dengan model TAPPS.

\section{Pembahasan Kepraktisan Perangkat Pembelajaran}

Respon positif juga diberikan oleh guru terhadap perangkat pembelajaran matematika dengan model TAPPS berbasis multimedia. Guru pelaksana dan 3 observer lain menyatakan bahwa perangkat yang dibuat sudah baik dan dapat membantu dalam pelaksanaan pembelajaran.

\section{Jurnal Refleksi Edukatika}




\section{Pembahasan Pembelajaran}

Hasil analisis terhadap disposisi matematis digunakan untuk menentukan efektivitas perangkat pembelajaran menyatakan bahwa perangkat pembelajaran yang digunakan untuk pembelajaran efektif.

Untuk menguji peningkatan disposisi matematis digunakan Uji normalized gain. Kegunaan dari uji normalized gain adalah untuk mengetahui sejauh mana peningkatan disposisi matematis sebelum dan sesudah pembelajaran.

Hasil perhitungan untuk peningkatan disposisi matematis dengan menggunakan normalized gain dapat dilihat pada Tabel. 4. berikut ini.

Tabel. 4. Hasil Peningkatan Disposisi Matematis

\begin{tabular}{|c|c|c|}
\hline Kriteria & $\begin{array}{c}\text { Jumlah } \\
\text { Peserta didik }\end{array}$ & Persentase \\
\hline Rendah & 0 & $0,00 \%$ \\
\hline Sedang & 10 & $26,3 \%$ \\
\hline Tinggi & 28 & $73,7 \%$ \\
\hline
\end{tabular}

Berdasarkan Tabel 4 dapat diketahui bahwa hasil peningkatan disposisi matematis peserta didik kelas uji coba perangkat dengan tingkat peningkatan rendah $0 \%$, sedang $26,4 \%$, dan tinggi $73,7 \%$. Rata-rata skor disposisi matematis yang diukur berdasarkan hasil pretest adalah 50,42. Rata-rata skor disposisi matematis yang diukur berdasarkan hasil postest adalah 86,97 dengan nilai maksimal adalah 100, sehingga rata-rata klasikal nilai normalized gain $\langle g\rangle$ adalah $74 \%$. Jadi secara rata-rata klasikal diperoleh nilai normalized gain $\langle g\rangle$ sebesar 74
$\%$ atau 0,74 yang berarti tafsiran peningkatan disposisi matematis yang terjadi termasuk kategori tinggi.

\section{KESIMPULAN}

Kesimpulan dari penelitian ini diambil berdasarkan analisis dan pembahasan.

1. Perangkat pembelajaran yang dikembangkan dalam penelitian ini valid.

2. Hasil penggunaan perangkat pembelajaran matematika dinyatakan praktis.

a. Peserta didik memberikan respon positif.

b. Guru memberikan respon positif.

3. Pembelajaran menggunakan model TAPPS berbasis Multimedia pada materi keliling dan luas segiempat menyatakan bahwa pembelajaran efektif, dinyatakan dengan terjadi peningkatan disposisi matematis yang tinggi pada kelas yang menggunakan model TAPPS berbasis Multimedia.

\section{DAFTAR PUSTAKA}

Anku, S.A. 1996. Fostering Student's Disposition towards Mathematics: a Case from a Canadian University. http://findarticles. com/p/articles/mi qa3673/is n4 v116/ai n28673065/. (diunduh 23 September 2011).

Arikunto, S. 2002b. Prosedur Penelitian. Jakarta: Rineka Cipta.

Catharina, T.A. 2006. Psikologi Belajar. Semarang: UNNES PRESS.

Hake, R.R. 1998. Interactive-engagement versus traditional methods: A sixthousand-student survey of mechanics test data for introductory physics courses. American Journal of Physics. Volume 66 No. 1. Hal 64-74. 
Hassard, Jack. 2000. Science As Inquiry. United States of America: Good Year Books.

Katz, L.G. 1985. Dispositions as Educational Goals. Teaching and Teacher Education. Volume 1 No. 4. Hal 301307.

Marina, M., Takac, D., dan Aleksandar, M. 2011. Multimedia Approach in Teaching Mathematics-Example of Lesson About The Definite Integral Application For Determining an Area. International Journal of Mathematical Education in Science and Technology. Volume 42 No. 2. Hal 175-187.

Maxwell, K. 2001. Positive Learning Disposition in Mathematics. http://www.education. auckland.ac.nz/webdav/site/education/ shared/about/research/docs/FOED $\% 20$ Papers/Issue\%2011/ACE_Paper_3_Iss ue_11.doc. (diunduh 21 November 2011).

Mayer, R. 2009. Multimedia Learning. Yogyakarta : Pustaka Pelajar

NCTM. 1989. Evaluation: Standard 10Mathematical http:/www.fayar.net Disposition. web/math/standards/Previous/CurrEvStd s/evals10.htm (diunduh 20 November 2011).

Pearson Education. 2000. Mathematical Disposition. http://www.teachervision. fen.com/math/teachertraining/55328.html?for_printing $=1$ (diunduh 23 September 2011).

Sudjana. 2002. Metoda Statistika. Bandung: Tarsito.
Sugiyono. 2010. Metode Penelitian Pendidikan Pendekatan Kualitatif, Kuantitatif, dan $R \& D$. Bandung: Alfabeta.

Sugiyono. 2011. Statistika untuk Penelitian. Bandung: Alfabeta.

Thiagarajan, S. 1978. Instructional Product Verification and Revision: 20 Questions and 200 Speculations. Educational Communication and Technology (An Analysis of Research Needs in Educational Communication and Technology), 26 (2) Part 2: 133-141. New York: Springer.

Thiagarajan, S., Semmel, D.S., dan Semmel, M.I. 1974. Instructional Development for Training Teachers of Exceptional Children. Minneapolis, Minnesota: Leadership Training Institute/Special Education, University of Minnesota.

Tishman, S., Jay E. dan Perkins, D.N. 1993 Teaching Thinking Dispositions: From Transmission to Enculturation. http://www.jstor.org/stable/1476695 (diunduh 20 November 2011).

Trianto. 2009. Mendesain Model Pembelajaran Inovatif Progresif. Jakarta: Kencana. 